\title{
Study on the Mechanical Properties of Solid Composite Propellant Used as a Gas Generator
}

\author{
Lia Junqueira Pimont ${ }^{1}$, Paula Cristina Gomes Fernandes², Luiz Fernando de Araujo Ferrão², \\ Marcio Yuji Nagamachi ${ }^{1}$, Kamila Pereira Cardoso ${ }^{1, \star}$
}

Pimont LJ (D) https://orcid.org/0000-0003-2515-9176 Fernandes PCG (D) https: / / orcid.org/0000-0003-2058-3699

Ferrão LFA (D) https://orcid.org/0000-0003-1294-8707

Nagamachi MY (D) https: / /orcid.org/0000-0001-7617-8647

Cardoso KP (D) https: / / orcid.org/0000-0001-5308-0188

\section{How to cite}

Pimont LJ; Fernandes PCG; Ferrão LFA; Nagamachi MY; Cardoso KP (2019) Study on the Mechanical Properties of Solid Composite Propellant Used as a Gas Generator. J Aerosp Technol Manag, 11, Special Edition: 7-10. https:// doi.org/10.5028/jatm.etmq.65

ABSTRACT: Gas generating propellants are used as initiators of liquid rocket propellants turbopumps and have as desired characteristic a high-volume production of low temperature gas. In this context, some formulations of composite propellant containing polyurethane (based on liquid hydroxyl-terminated polybutadiene), guanidine nitrate, ammonium perchlorate, and additives were evaluated and characterized in order to verify their potential as gas generator propellant, as well as to evaluate the influence of additives on mechanical properties. The formulations were prepared, analyzed, and tested for mechanical properties.

KEYWORDS: Gas generators; Solid propellant; Propellant additives; Guanidines; Nitrates.

\section{INTRODUCTION}

The composition of solid propellants consists basically of a binder such as polyurethanes based on liquid hydroxyl-terminated polybutadiene (HTPB), an oxidizer such as ammonium perchlorate, curing agent, plasticizer, metallic additives, ballistic modifiers, among others (Kishore and Sridhara 1999). The propellant may have different purposes depending on its formulation, ranging from low-temperature gas generator to rocket-propellant.

The gas generator propellant, in turn, can have a wide range of applications: in-car safety systems (airbags), fire extinguishers (Puccio et al. 2011), or even as a liquid rocket-motor turbopump initiator (Salgansky et al. 2019; Harikrishnan et al. 2018). This type of material has as its main characteristic the production of a large volume of gases in a small-time interval (Puccio et al. 2011). Besides, these gases are produced with temperatures lower than propellants commonly used in solid propulsion (Almeida and Pagliuco 2014). The low adiabatic flame temperature imposes a challenge for this type of propellant to ignite and maintain a self-sustaining burning.

Therefore, this work aimed to evaluate and develop a propellant formulation that produces gases with temperatures below $1100{ }^{\circ} \mathrm{C}$ and with appropriate mechanical properties (Almeida and Pagliuco 2014). The temperature is limited due to the application of this propellant in turbopumps and must not exceed the temperature that would cause damage to their blades. The mechanical

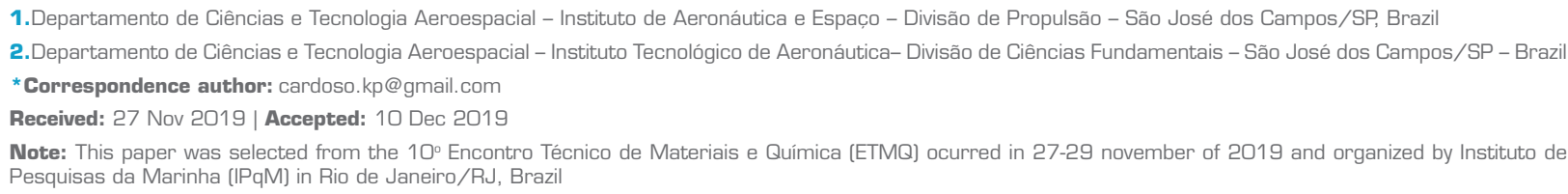


properties must be adequate to prevent the formation of fractures in the gas generator grain, which otherwise could cause an explosion during burning. Thermodynamic calculations were conducted to determine the gas temperature and optimize the formulation. The formulations were prepared, analyzed, and submitted to mechanical tests.

\section{MATERIALS AND METHODS}

The propellant samples were prepared based on the composition described in Table 1, using HTPB (Liquiflex - batch 19/90) as a binder; as solid load: ammonium perchlorate (IAE - batch 002/2014) and guanidine nitrate (GUNI, Chemical Point - batch CP4139) as oxidizers, and copper acetylacetonate (CuAA), synthesized according to Cardoso et al. (2019), as a catalyst for thermal degradation of HTPB. Dioctyl adipate (DOA, Scandiflex - batch 712040004) was used as a plasticizer, silicone oil (Anhydrol batch 32701) as a ballistic modifier, iron oxide $\left(\mathrm{Fe}_{2} \mathrm{O}_{3}\right.$, IAE - batch 01/UCA/10) as a burning catalyst, tepanol (IAE Synthesis Laboratory) as a bonding agent and isophorone diisocyanate (IPDI, Hülls - batch 11/0016) as a curing agent.

Table 1. Formulation of propellant samples [\% by mass].

\begin{tabular}{|c|c|c|c|c|}
\hline \multirow{2}{*}{ Materials } & \multicolumn{3}{|c|}{ Samples } \\
\cline { 2 - 5 } & A & B & C & D \\
\hline HTPB & 24.01 & 24.15 & 23.77 & 69.89 \\
\hline Solids fraction & 69.78 & 70.18 & 69.08 & 0.57 \\
\hline $\mathrm{Fe}_{2} \mathrm{O}_{3}$ & 0.58 & 0.00 & 0.57 & 2.97 \\
\hline DOA & 2.00 & 2.01 & 1.98 & 0.99 \\
\hline Silicon oil & 1.00 & 1.01 & 0.99 & 0.99 \\
\hline Bonding agent & 0.00 & 0.00 & 0.99 & 2.51 \\
\hline IPDI & 2.63 & 2.65 & 2.61 & \\
\hline
\end{tabular}

The mechanical properties were obtained through a ZWICK 1474 optical strain transducer, according to the STANAG 4506 technical standard. The hardness tests were performed on an INSTRON S1 durometer based on ASTM D2240. All formulations of propellant grain samples have been evaluated for gas-burning temperature using the Fraunhofer ICT program version 7.0 (2004).

\section{RESULTS}

An essential requirement for a gas generator propellant for aerospace application is the temperature of the gases exiting the nozzle throat, which has to be lower than $1100^{\circ} \mathrm{C}$ (Almeida and Pagliuco 2014). All the developed formulations met this requirement, with temperatures in the order of $890^{\circ} \mathrm{C}$. Another important aspect is the amount of carbon generated in the combustion of this type of propellant, typically in the range of 5-15\% (Sutton and Vriesen 1979), resulting from the low oxidizer/fuel ratio to avoid high temperatures. In the formulations developed in this work, this issue was mitigated by the use of an oxidizer with low combustion enthalpy (guanidine nitrate), resulting in a fraction of residual carbon in the order of $1 \%$. Regarding the mechanical tests, the samples were analyzed for their tensile and deformation resistance (Fig. 1).

Figure 1 shows that the removal of the burning catalyst (B) did not modify the mechanical properties in relation to the reference sample (A). On the other hand, the incorporation of the bonding agent (C), as well as the plasticizer (D), increased the maximum stress and strain of the samples. Regarding the hardness (Shore A), all samples presented values in the order of $75 \pm 1$. Therefore, the insertion of the bonding agent modified the profile of the stress versus strain curve, with a second apparent linear region before the maximum stress, related to the interaction between the bonding agent and the solid load (Sciamareli et al. 2002). 


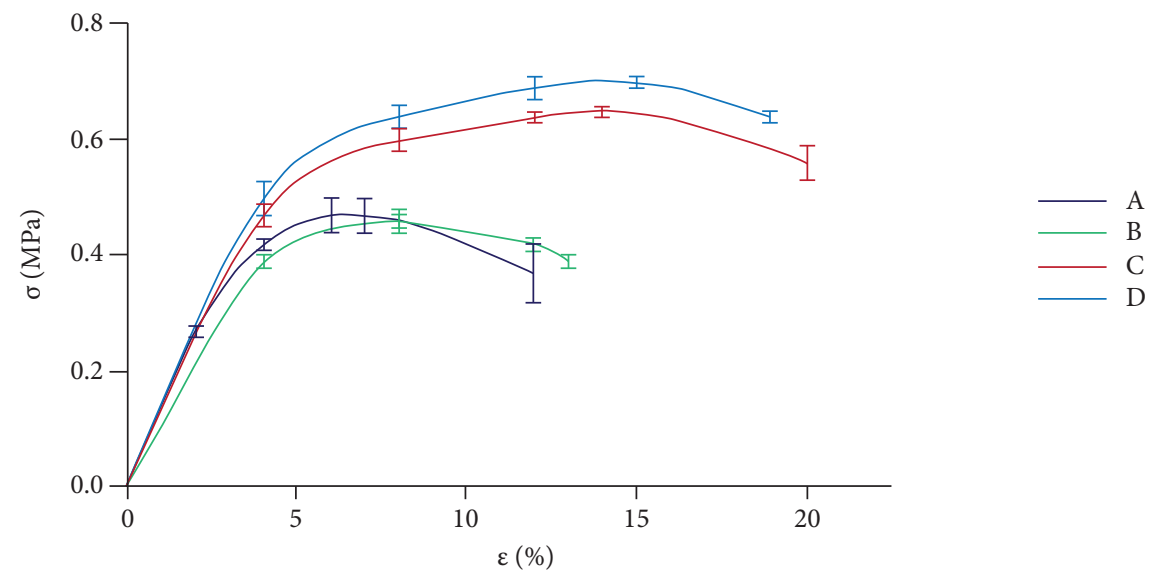

Figure 1. Comparative stress curve versus elongation of samples $A, B, C$, and $D$.

\section{CONCLUSION}

This work studied formulations of solid composite propellant of gas generator type, evaluating the influence of additives on the material mechanical properties. The incorporation of the bonding agent was responsible for the most important variations, causing an increase in maximum stress and strain, bringing the material closer to ideal properties. Changes in the concentration of other additives (burning catalyst, plasticizer) did not show significant variations.

\section{ACKNOWLEDGMENTS}

The authors thank IAE technicians and researchers for their support and availability.

\section{FUNDING}

Coordenação de Aperfeiçoamento de Pessoal de Nível Superior [http://doi.org/10.13039/501100002322]

Grant 88887.142345/2017-00

Fundação de Amparo à Pesquisa do Estado de São Paulo [http://doi.org/10.13039/501100001807]

Grants 2019/03042-2 and 2019/03729-8

Conselho Nacional de Desenvolvimento Científico e Tecnológico [http://doi.org/10.13039/501100003593]

Grants 422016/2017-9, 309051/2016-9, 157662/2018-7 and 406107/2016-5

\section{AUTHORS' CONTRIBUTION}

Conceptualization, Nagamachi MY; Methodology, Pimont LJ, Nagamachi MY, and Cardoso KP, Data acquisition, Pimont LJ and Fernandes PCG; Writing - Original Draft, Pimont LJ, Fernandes PCG, and Cardoso KP; Writing - Review and Editing, Cardoso KP and Ferrão LFA; Funding acquisition, Cardoso KP and Ferrão LFA; Resources, Nagamachi MY; Supervision, Nagamachi MY, Ferrão LFA, and Cardoso KP. 


\section{REFERENCES}

Almeida DS, Pagliuco CMM (2014) Development Status of the L75: A Brazilian liquid propellant rocket engine. J Aerosp Technol Manag 6(4):475-484. https://doi.org/10.5028/jatm.v6i4.386

Cardoso KP, Ferrão LFA, Kawachi EY, Gomes JS, Nagamachi MY (2019) Ballistic performance of paraffin-based solid fuels enhanced by catalytic polymer degradation. J Propul Power 35(1):115-124. https://doi.org/10.2514/1.B36977

Harikrishnan ES, Hariharanath B, Vineeth GM, Purushothaman P (2018) Thermokinetic analysis and performance evaluation of guanidinium azotetrazolate based gas generating composition for testing of solid rocket motor nozzle closures. Propellants Explos Pyrotech 43(10):1006-1012. https://doi.org/10.1002/prep.201800103

Kishore K, Sridhara K (1999) Solid propellant chemistry: Condensed phase behavior of ammonium perchlorate-based solid propellants. New Delhi (India): Defense Research \& Development Organization Ministry of Defense.

Puccio R, Maggi F, Columbo G, DeLuca LT, Amicis R (2011) Low Temperature Gas Generator Propellants. Proceedings of the: CEAS The International Conference of the European Aerospace Societies; Venice, Italy.

Salgansky EA, Lutsenko NA, Levin VA, Yanovskiy LS (2019) Modeling of solid fuel gasification in combined charge of low-temperature gas generator for high-speed ramjet engine. Aerosp Sci Technol 84:31-36. https://doi.org/10.1016/j.ast.2018.10.029

Sciamareli J, Takahashi M, Teixeira J, Iha K (2002) Propelente sólido compósito polibutadiênico: Influência do agente de ligação. Quím Nova 25(1):107-110. https://doi.org/10.1590/S0100-40422002000100018

Sutton ES, Vriesen CW (1979) Gas generator propellants for aerospace applications. Proceedings of the: AIAA/SAE/ASME 15th Joint Propulsion Conference; Las Vegas, United States. https://doi.org/10.2514/6.1979-1325 